\title{
IIII Racial/Ethnic Disparities in Exercise and Dietary Behaviors of Middle-Aged and Older Adults
}

\author{
Kristin J. August, PhD and Dara H. Sorkin, PhD
}

Division of General Internal Medicine and Primary Care and Health Policy Research Institute, University of California Irvine, Irvine, CA, USA.

BACKGROUND: Differences in health behaviors may be important contributors to racial/ethnic disparities in the health status of adults. Studies to date have not compared whether there are health behavior differences in exercise and dietary behaviors among middle-age and older adults in the four largest racial/ethnic categories.

OBJECTIVE: To investigate racial/ethnic differences in exercise and dietary behaviors of middle-aged and older adults.

DESIGN: We used data from the 2007 California Health Interview Survey. Multivariable logistic regression was used to examine interactions between age and race/ ethnicity in predicting two categories of health behaviors. Analyses were conducted adjusting for sociodemographic characteristics, health insurance status, and healthcare utilization.

PARTICIPANTS: A population-based sample of 33,189 California adults 45 years old and older: 26,522 nonHispanic whites, 1,686 African American/blacks, 2,565 Asian/Pacific Islanders (1,741 English-proficient; 824 limited English-proficient), and 2,416 Latinos (1,538 English-proficient; 878 limited English-proficient).

MAIN MEASURES: Self-report leisure-time physical activity (moderate and vigorous) and daily consumption of fruits and vegetables.

KEY RESULTS: Racial/ethnic minorities generally engaged in less healthy exercise and dietary behaviors than whites, with differences more pronounced in middle adulthood. The disparities were the greatest among English-proficient minorities. Specifically, among middle-aged respondents, all racial/ethnic minorities engaged in less vigorous physical activity than whites (ORs range $=0.28$ to $0.73 ; 95 \%$ CI range $=0.16-1.00$ ) . Additionally, middle-aged, English-proficient minorities engaged in less moderate physical activity compared to whites (ORs range $=0.57$ to 0.67 ; 95\% CI range $=$ 0.45-0.79). Furthermore, middle-aged, English-proficient Latinos had a poorer diet than whites $(\mathrm{OR}=0.54$; 0.39-0.75). Few significant racial/ethnic differences emerged in the exercise and dietary behaviors of older adults.

CONCLUSIONS: Racial/ethnic disparities in exercise and dietary behaviors are most notable among middleaged, acculturated minorities. Results highlight the

Received May 19, 2010

Revised August 30, 2010

Accepted September 2, 2010

Published online September 24, 2010 need to promote positive exercise and dietary behaviors during critical preventive ages, when racial/ethnic disparities are large and the potential to prevent chronic disease is great.

KEY WORDS: diet; exercise; older adults; racial and ethnic disparities; California Health Interview Survey.

$\mathrm{J}$ Gen Intern Med 26(3):245-50

DOI: $10.1007 / \mathrm{s} 11606-010-1514-7$

(C) The Author(s) 2010. This article is published with open access at Springerlink.com

\section{INTRODUCTION}

Racial/ethnic disparities in health status are well established throughout the lifespan, such that racial/ethnic minorities generally fare worse than non-Hispanic whites on most measures of physical health. ${ }^{1,2}$ Racial/ethnic minorities, particularly African American/blacks, have a greater risk of developing chronic conditions involving lifestyle factors, such as heart disease, ${ }^{3}$ high blood pressure, ${ }^{4}$ and diabetes, ${ }^{5}$ compared to whites. These disparities are of particular concern given that demographic shifts in the population are expected to be most pronounced among older racial/ethnic minorities, ${ }^{6}$ potentially widening the disparities gap.

A growing body of evidence indicates that the earlier healthenhancing behaviors are adopted, the greater the likelihood that the chronic illnesses that differentially affect older racial/ ethnic minorities can be reduced or prevented. ${ }^{7}$ One such health behavior, regular physical activity, has been found to be critical for preventing morbidity and mortality, ${ }^{8,9}$ especially among older adults. ${ }^{2}$ Although findings are mixed as to whether higher levels of work-related physical activities lead to better health, ${ }^{10,11}$ population-based studies provide evidence that leisure-time physical activity is a predictor of overall health and physical functioning. ${ }^{12,13}$ Despite evidence that physical activity decreases with age for all groups, racial/ ethnic minorities remain less likely to be physically active in later life compared to non-Hispanic whites. ${ }^{14}$

A dietary pattern rich in fruits and vegetables is another important health behavior for the prevention of chronic disease. Findings from long-term prospective studies suggest that the frequency of fruit and vegetable intake is inversely associated with cardiovascular disease, diabetes, some cancers, and all-cause mortality, even after adjusting for other health behaviors. ${ }^{15,16}$ Evidence is mixed regarding dietary differences by race/ethnicity, with some research suggesting 
that fruit/vegetable consumption is comparable for African American/black and Latino middle-aged and older adults compared to non-Hispanic whites. ${ }^{17}$ Other studies have found that African American/blacks consume less fruits and vegetables and whites, however. ${ }^{18}$ To date, little population-based evidence exists on differences between Asian/Pacific Islanders and non-Hispanic whites with regard to fruit and vegetable consumption in middle and later adulthood.

Acculturation may play an important role in whether health behaviors vary by race/ethnicity. ${ }^{19,20}$ It has been proposed that while immigrants come to the U.S. with relatively advantageous health behaviors, including physical activity and diet, such behaviors deteriorate the longer immigrants live in this country. English-language proficiency is one index of acculturation that has been found to be related to health behaviors. For example, evidence suggests that Latinos who are more acculturated, or speak English well, are less likely to engage in healthy behaviors compared to Latinos who are less acculturated. ${ }^{17,21,22}$

Despite the available evidence on racial/ethnic differences in health behaviors, very few studies have examined the frequency with which Asian/Pacific Islanders engage in leisure-time physical activity and their dietary behaviors relative to non-Hispanic whites, and rarely have all four major racial/ethnic categories been examined together in a population-based data set. Moreover, few studies have assessed racial/ethnic differences across different age groups in adulthood. ${ }^{17}$ Accordingly, the current study used data from the 2007 California Health Interview Survey (CHIS), a large population-based sample of California adults, to examine how reports of exercise and dietary behaviors of African American/ black, Latino, and Asian/Pacific Islander middle-aged and older adults compared to those of non-Hispanic whites living in California. Given evidence of the importance of acculturation in influencing individuals' engagement in health behaviors, the current study further sought to examine how English language proficiency contributed to potential disparities in health behaviors for Latinos and Asian/Pacific Islanders. We hypothesized that racial/ethnic disparities in health behaviors would be more pronounced in African American/blacks and less acculturated Asian/Pacific Islanders and Latinos compared to whites. The current study also sought to examine age differences in racial/ethnic disparities in health behaviors in light of evidence that the physically hardiest of individuals, regardless of race/ ethnicity, survive into late adulthood. ${ }^{23,24}$

\section{METHODS}

\section{Procedure}

Data for the current study were derived from the 2007 California Health Information Survey (CHIS), a biannual, random-digit dial telephone survey, representative of the Californian non-institutionalized population. Comparable to response rates of other scientific telephone surveys conducted in California, the response rate ranged from $15.9 \%$ to $22.1 \%$, depending on the mode of data collection. ${ }^{25}$ Interviews were conducted in five languages based on 2000 Census data of the languages spoken most often by Californian residents (English, Spanish, Chinese, Vietnamese, or Korean). The survey underwent refereed translation processes and extensive cultural adaptation to ensure cross-cultural equivalence across items. ${ }^{25}$

\section{Sample}

The analytic sample included 33,189 adults 45 years of age or older, as we only were interested in examining differences in exercise and dietary behaviors for middle-aged and older adults in four racial/ethnic categories. This included 26,522 non-Hispanic white, 1,686 African American/black, 2,565 Asian/Pacific Islander (1,741 English-proficient; 824 limited English-proficient), and 2,416 Latino (1,538 English-proficient adults; 878 limited English-proficient) respondents. All white and African American/black respondents were English-proficient. The sample was weighted to account for the complex sampling design, as well as to accurately represent variance estimates. ${ }^{25}$

\section{Measures}

Health Behaviors. Two indicators of leisure-time physical activity were evaluated in the current study by prompting participants to think about physical activities or exercise they do in their free time. First, engagement in the recommended amount of moderate physical activity (5 days per week, 30 minutes per day) was assessed by asking participants to “... think about activities that take moderate physical effort, such as walking, bicycling, swimming, dancing, or gardening." Participants then rated whether and how often (how many days per week and how much time per day) they spent engaging in moderate physical activity. Second, engagement in the recommended amount of vigorous physical activity (3 days per week, 20 minutes per day) was assessed by asking participants to "...think about activities that take hard physical effort, such as aerobics, running, soccer, fast bicycling, or fast swimming." Frequency and duration was assessed using a similar set of questions as moderate physical activity. Responses were coded to indicate if respondents engaged in the recommended amount of both moderate and vigorous physical activity ( $1=$ did not engage in recommended amount; 2 =did engage in recommended amount).

To assess healthy diet, daily consumption of the recommended amount of fruits and vegetables was asked, i.e., "During the past month, how many times per day, week or month did you eat fruit? Do not count juices" and "During the past month, how many times did you eat vegetables, like green salad, green beans, or potatoes? Do not include fried potatoes." Participants rated how many and how often they ate fruit or vegetables $(1=$ per day, $2=$ per week, 3=per month). A variable was derived to indicate frequency of daily fruit and vegetable consumption. As guidelines suggest a minimum of five servings of fruits and vegetables daily for middle-aged and older adults, ${ }^{26}$ the variable representing frequency of fruits and vegetable consumed per day was dichotomized ( $1=$ ate fruits and vegetables less than five times per day, 2 =ate fruits and vegetables five or more times per day).

Covariates. Variables identified in previous research on racial/ ethnic disparities in health behaviors that exhibited significant 
racial/ethnic differences in the current sample were treated as covariates. These included sociodemographic characteristics, such as gender, marital status $(1=$ not currently married, $2=$ currently married $)$, education level $(1=<$ high school, $2=\geq$ high school), and income $(1=<\$ 20,000,2=\geq \$ 20,000)$. In addition, health insurance status $(1=$ not currently insured, $2=$ currently insured $)$ and healthcare utilization $(1=$ no doctor visit in the past year, $2=$ doctor visit in the past year) were included as covariates.

\section{Statistical Analyses}

SAS Callable SUDAAN Release 9.0.2 (Research Triangle Institute, Research Triangle Park, NC) was used to conduct analyses to account for the complex sampling design, as well as to use weighted effects for accurate variance estimates. To examine racial/ethnic differences in sociodemographic characteristics, we conducted bivariate analyses using Chi-square tests. To examine racial/ethnic differences in each health behavior, we conducted three multivariable logistic regressions, testing the interaction of race by age. If interactions were significant, we then stratified results for each age group (45-64 vs. 65-85) for ease of interpretation. Adjustments were made for gender, marital status, education, income, insurance status, and healthcare utilization in all multivariate analyses.

\section{RESULTS}

Sociodemographic characteristics for the racial/ethnic categories, stratified by age group, are presented in Table 1. Latinos who were limited English-proficient were the least likely to have more than a high school degree $(20.7 \%)$, have a household income equal to or greater than $\$ 20,000 /$ year $(48.5 \%)$, be continuously insured (60.3\%), and have had a doctor visit in the past year (74.1\%) compared to the other racial/ethnic categories $(P<0.001)$. In addition, limited English-proficient Asian/Pacific Islanders (98.8\%) and Latinos (97.8\%) were more likely to report being foreign-born compared to the other racial/ethnic categories $(P<0.001)$.

The adjusted results of racial/ethnic differences in exercise and dietary behaviors, stratified by age group are presented in Table 2. Non-Hispanic whites reported engaging in all healthenhancing behaviors more frequently than all racial/ethnic minorities in middle, but not late, adulthood. As seen in Table 2, 45-64 year old African American/blacks, as well as English-proficient Asian/Pacific Islanders and Latinos, were significantly less likely to engage in moderate physical activity compared to whites. Only limited English-proficient Asian/ Pacific Islanders $\geq 65$ years old were significantly more likely to engage in moderate physical activity compared to whites. The age by race/ethnicity interaction was significant $\left(\chi^{2}\right.$ difference $=$ 96.07, $5 d f, P<0.001)$.

All racial/ethnic minorities 45-64 years old were significantly less likely to engage in vigorous physical activity compared to whites. Only limited English-proficient Asian/ Pacific Islanders $\geq 65$ years were significantly less likely to engage in vigorous physical activity compared to whites. The age by race/ethnicity interaction was significant $\left(\chi^{2}\right.$ difference $=$ 34.96, 5 df, $P<0.001)$.

Finally, only English-proficient Latinos 45-64 years old were significantly less likely to eat the recommended amount of fruits and vegetables daily compared to whites. Among respondents $\geq 65$, African American/blacks and limited English-proficient Latinos were significantly less likely to eat the recommended amount of fruits and vegetables daily compared to whites. The age by race/ethnicity interaction was significant $\left(\chi^{2}\right.$ difference $\left.=37.17,5 d f, P<0.001\right)$.

\section{DISCUSSION}

The current study sought to examine racial/ethnic differences in exercise and dietary behaviors among middle-aged and

Table 1. Sociodemographic Characteristics, Healthcare Utilization, and Health-Enhancing Behaviors of Respondents by Race/Ethnicity $(N=33,189)$

\begin{tabular}{|c|c|c|c|c|c|c|c|}
\hline \multirow[b]{2}{*}{ Characteristic } & $\begin{array}{l}\text { Non-Hispanic } \\
\text { white }(n=26,522)\end{array}$ & $\begin{array}{l}\text { African American/ } \\
\text { black }(n=1,686)\end{array}$ & $\begin{array}{l}\text { Asian/Pacific } \\
\text { Islander -EP } \\
(n=1,741)\end{array}$ & $\begin{array}{l}\text { Asian/Pacific } \\
\text { Islander - LEP } \\
(n=824)\end{array}$ & $\begin{array}{l}\text { Latino -EP } \\
(n=1,538)\end{array}$ & $\begin{array}{l}\text { Latino - LEP } \\
(n=878)\end{array}$ & \\
\hline & \multicolumn{7}{|c|}{ (\%) $n$} \\
\hline \multicolumn{8}{|l|}{ Age } \\
\hline $45-64$ & (67.5) 14,855 & (74.4) 1,063 & $(69.2) 1,180$ & $(61.8) 443$ & (78.0) 1,167 & $(78.0) 617$ & $P<0.001$ \\
\hline $65-85$ & (32.5) 11,667 & $(25.6) 623$ & $(30.8) 561$ & $(38.2) 381$ & $(22.0) 371$ & $(22.0) 261$ & \\
\hline Gender (female) & (52.8) 16,138 & (54.9) 1,093 & (57.0) 1,029 & $(53.8) 470$ & (52.1) 937 & $(46.3) 518$ & $P=0.01$ \\
\hline Marital status (married) & (66.2) 13,523 & $(39.0) 554$ & (75.6) 1,190 & $(79.0) 611$ & (66.3) 796 & $(66.0) 508$ & $P<0.001$ \\
\hline Education ( $\geq$ high school ) & (93.4) 25,268 & $(89.2) 1,524$ & (94.7) 1,686 & $(67.7) 600$ & $(71.2) 1,222$ & $(20.7) 210$ & $P<0.001$ \\
\hline Income $(\geq \$ 20,000 /$ year) & (89.8) 22,938 & (75.9) 1,230 & (86.8) 1,532 & (54.9) 405 & (79.7) 1,171 & $(48.5) 375$ & $P<0.001$ \\
\hline Nativity (foreign born) & (8.7) 1,961 & (7.8) 110 & $(77.2) 1,229$ & $(98.8) 822$ & (34.3) 511 & $(97.8) 841$ & $P<0.001$ \\
\hline Currently insured & (92.9) 24,891 & (88.5) 1,534 & (91.6) 1,595 & (78.4) 656 & (86.4) 1,341 & $(60.3) 595$ & $P<0.001$ \\
\hline Doctor visit in past year & (89.0) 23,837 & (89.1) 1,521 & (86.6) 1,501 & $(74.8) 648$ & (83.6) 1,333 & (74.1) 687 & $P<0.001$ \\
\hline $\begin{array}{l}\text { Recommended moderate } \\
\text { physical activity }\end{array}$ & (30.7) 8,525 & (21.9) 366 & (27.1) 494 & (36.3) 294 & (23.2) 372 & (29.0) 219 & $P<0.001$ \\
\hline $\begin{array}{l}\text { Recommended vigorous } \\
\text { physical activity }\end{array}$ & (14.6) 3,633 & (11.3) 166 & (12.3) 237 & (4.7) 57 & (11.5) 187 & (3.9) 44 & $P<0.001$ \\
\hline $\begin{array}{l}\text { Recommended amount } \\
\text { of daily fruits and vegetables }\end{array}$ & (8.7) 2,613 & (6.0) 112 & $(8.3) 155$ & (6.1) 43 & (5.1) 97 & (2.5) 29 & $P<0.001$ \\
\hline
\end{tabular}

Note. EP=English-proficient; LEP=limited English-proficient. All percentages are weighted. Sample sizes are unweighted. 
Table 2. Adjusted Racial/Ethnic Differences in Leisure-Time Physical Activity and Dietary Behaviors for Middle-aged (45-64) and Older $(65-85)$ Adults $(N=33,189)$

\begin{tabular}{lcc}
\hline \hline & $\begin{array}{l}\text { Middle-aged } \\
\text { adults }(n=19,325)\end{array}$ & $\begin{array}{l}\text { Older adults } \\
(n=13,864)\end{array}$ \\
\cline { 2 - 3 } & Adjusted Odds Ratio $(95 \% \mathrm{Cl})$ \\
\hline \multicolumn{3}{c}{ Recommended moderate physical activity: 5 days/week, 30 minutes/day } \\
Non-Hispanic white & $\mathrm{REF}$ & $\mathrm{REF}$ \\
African American/black & $0.57(0.45,0.73)$ & $0.76(0.57,1.02)$ \\
Asian/Pacific Islander - EP & $0.67(0.56,0.79)$ & $1.31(1.00,1.69)$ \\
Asian/Pacific Islander - LEP & $0.91(0.66,1.25)$ & $2.17(1.51,3.12)$ \\
Latino - EP & $0.60(0.49,0.74)$ & $1.11(0.80,1.54)$ \\
Latino - LEP & $0.87(0.61,1.23)$ & $1.31(0.88,1.95)$ \\
Recommended vigorous physical activity: 3 days/week, 20 minutes/day \\
Non-Hispanic white & REF & REF \\
African American/black & $0.73(0.53,1.00)$ & $1.09(0.70,1.68)$ \\
Asian/Pacific Islander - EP & $0.68(0.52,0.88)$ & $1.38(1.00,1.92)$ \\
Asian/Pacific Islander - LEP & $0.36(0.23,0.55)$ & $0.26(0.13,0.53)$ \\
Latino - EP & $0.73(0.54,0.98)$ & $1.12(0.66,1.91)$ \\
Latino - LEP & $0.28(0.16,0.49)$ & $0.67(0.28,1.57)$ \\
Recommended amount of daily & fruit and vegetable consumption \\
Non-Hispanic white & REF & REF \\
African American/black & $0.74(0.50,1.09)$ & $0.50(0.32,0.77)$ \\
Asian/Pacific Islander - EP & $0.74(0.54,1.01)$ & $1.30(0.89,1.90)$ \\
Asian/Pacific Islander - LEP & $0.68(0.37,1.28)$ & $0.99(0.51,1.91)$ \\
Latino - EP & $0.54(0.39,0.75)$ & $1.06(0.60,1.87)$ \\
Latino - LEP & $0.57(0.29,1.13)$ & $0.23(0.10,0.55)$ \\
\hline
\end{tabular}

Note: Adjusted models include gender, marital status, education, income, insurance status, and healthcare utilization. $E P=$ English-proficient; $L E P=$ limited English-proficient.

older adults, using population-based data representative of the Californian non-institutionalized population. The low frequency with which respondents reported engaging in these health behaviors, irrespective of age and race or ethnicity, highlights the need to promote these health-enhancing behaviors. Nonetheless, important racial/ethnic differences existed, especially among English-proficient, middle-aged adults.

Specifically, with regard to physical activity, middle-aged racial/ethnic minorities generally fared worse than whites, although these disparities diminished in late adulthood. This was particularly true among more acculturated, Englishproficient minorities, including African American/blacks. These results are consistent with other studies, which have demonstrated racial/ethnic disparities in leisure-time physical activity, such that racial/ethnic minorities, including African American/blacks, ${ }^{27,28}$ Latinos, ${ }^{29}$ and Asian/Pacific Islanders, ${ }^{30,31}$ tended to be less physically active compared to whites. $^{32,33}$ As they come to the United States, immigrants tend to be healthier, but over time, adopt a less healthy lifestyle. ${ }^{34}$ The generally low rates of engagement in physical activity across all racial/ethnic categories highlight the need to consider important barriers to exercise. For example, disparities in physical activity may be a function of health-related issues, ${ }^{35-37}$ as well as the lack of environmental and social resources available to these individuals, ${ }^{35,38}$ such as the lack of safe public parks or recreational facilities. ${ }^{37}$ Moreover, physically demanding occupations, which are common among individuals of lower socioeconomic status, usually involve less flexible work schedules and less opportunities for engagement in leisure-time activities. ${ }^{39}$ Although health issues may serve as a barrier to exercise, paradoxically, older adults with a chronic condition may be motivated to exercise, ${ }^{35}$ which might partially explain why rates of engagement in moderate activity are higher among this age group. Another possible explanation for the lack of disparities in late adulthood is that these older individuals, regardless of race or ethnicity, may be physically resilient individuals who survived the various chronic conditions and associated disability of middle adulthood. ${ }^{24}$

Results for healthy diet were similar to those for physical activity. In general, more acculturated minorities fared worse than whites. Evidence is mixed about racial/ethnic disparities in healthy diet and many studies have not focused specifically on middle-aged or older adults. In one exception, researchers found that older African American/blacks had a lower intake of fruits and vegetables compared to whites, ${ }^{27}$ which is consistent with the results of the current study. Results from the current study also revealed a disparity in healthy diet for middle-aged English-proficient Asian/Pacific Islanders and Latinos compared to whites, consistent with an acculturation effect. ${ }^{22}$ In addition, studies on disparities in diet have focused on how the lower socioeconomic status of these minorities may limit the availability, affordability, and choice of healthy food options. Given that fruits and vegetables are often more costly than less healthy options, ${ }^{40}$ less accessible in lower-income neighborhoods, and less likely to be chosen by individuals with lower educational attainment, ${ }^{18,41}$ racial/ethnic minorities with lower incomes and education levels may be less likely to consume a healthy diet. Results of the current study suggest that limited English-proficient Latinos had the lowest educational attainment compared to the other racial/ethnic categories, which might help explain their dietary disadvantage compared to non-Hispanic whites. We adjusted for socioeconomic variables, however, and disparities still existed, suggesting that other relevant variables such as specific knowledge related to nutrition acquired from nutrition education messages - a majority of which are in English - could be influencing the results of the current study. ${ }^{42}$

\section{Study Limitations and Future Directions}

In evaluating the results of the current study, some limitations and directions for future research should be noted. First, results cannot be applied to individuals residing in other areas of the country in which diet and exercise behaviors may differ as a function of availability of healthy food options, opportunities for physical activity, and regional norms. For example, rates of engagement in health-enhancing behaviors may depend on whether individuals are from rural or urban areas, with minorities in rural areas demonstrating healthier dietary behaviors. ${ }^{43}$ Second, only a subsection of health behaviors were examined. Other behaviors (e.g., fat consumption) may exhibit a different pattern of findings. For example, although we found racial/ethnic differences in fruit and vegetable consumption, a nationally representative sample of older African American/blacks and whites found no difference in the amount of fat consumption. ${ }^{27}$ In a related vein, only leisure-time physical activity was assessed, not physical activity as part of the work day or for transportation, the latter of which may be more common in middle-aged minority respondents. ${ }^{44}$

Results from the current study also suggest avenues for future research. First, researchers need to better understand particular risk and protective factors that make some minor- 
ities more vulnerable to adopting unhealthy lifestyles. Second, physicians need to counsel patients about culturally-appropriate ways to engage in a healthy diet and increase exercise and to provide direct assistance in ways to access community resources. Finally, intervention strategies tailored to the unique life contexts of specific racial/ethnic categories should be implemented at multiple levels to encourage healthy exercise and dietary behaviors, including the individual (e.g., low-literacy nutrition information), ${ }^{45}$ social network (e.g., involvement of the family and community, such as churchbased interventions), ${ }^{46}$ as well as public health programs and health policies (e.g., Eat Better \& Move More program, ${ }^{47}$ zoning to improve neighborhood designs that promote physical activity and access to healthy food outlets). ${ }^{48}$

\section{CONCLUSION}

A healthy diet and exercise, if adopted, can reduce or prevent many of the chronic illnesses that affect older adults. More effort is needed to promote positive exercise and dietary behaviors earlier in life to have the greatest impact on reducing prominent racial/ethnic disparities and preventing disease.

Acknowledgments: The authors would like to thank Drs. Sheldon Greenfield, Sherrie Kaplan, Quyen Ngo-Metzger, and Dana Mukamel for their invaluable feedback on earlier versions of this manuscript. Dr. Sorkin received support from a KO1 award (NIDDK DK078939).

\section{Conflict of Interest: None disclosed.}

Open Access: This article is distributed under the terms of the Creative Commons Attribution Noncommercial License which permits any noncommercial use, distribution, and reproduction in any medium, provided the original author(s) and source are credited.

Corresponding Author: Dara H. Sorkin, PhD; Division of General Internal Medicine and Primary Care and Health Policy Research Institute, University of California Irvine, 100 Theory, Suite 110, Irvine, CA 92617, USA (e-mail: dsorkin@uci.edu).

\section{REFERENCES}

1. Ren X, Amick BC, Williams DR. Racial/ethnic disparities in health: the interplay between discrimination and socioeconomic status. Ethn Dis. 1999;9(2):151-165.

2. Kim JS, Bramlett MH, Wright LK, Poon LW. Racial differences in health status and health behaviors of older adults. Nurs Res. 1998;47 (4):243-250.

3. Mensah GA, Brown Dw. An overview of cardiovascular disease burden in the United States. Health Aff. 2007;26(1):38-48.

4. Burt VL, Cutler JA, Higgins M, et al. Trends in the prevalence, awareness, and control of hypertension in the adult US population: Data from the health examination surveys. Hypertension. 1995;26: 60-69.

5. Narayan KM, Boyle JP, Thompson TJ, Sorensen SW, Williamson DF. Lifetime risk for diabetes mellitus in the United States. JAMA. 2003;290 (14): 1884-1890

6. U.S. Census Bureau. State and national population projections. http:// www.census.gov/population/www/projections/popproj.html. Accessed September 04, 2010.
7. Ruigomez A, Alonso J, Anto JM. Relationship of health behaviours to five-year mortality in an elderly cohort. Age Ageing. 1995;24(2):113-119.

8. Kaplan GA, Seeman TE, Cohen RD, Knudsen LP, Guralnik J. Mortality among the elderly in the Alameda County Study: behavioral and demographic risk factors. Am J Public Health. 1987;77(3):307-312.

9. Dubbert PM, Carithers T, Sumner AE, et al. Obesity, physical inactivity, and risk for cardiovascular disease. Am J Med Sci. 2002;324 (3): 116-126.

10. Gutierrez-Fisac JL, Guallar-Castillon P, Diez-Ganan L, Lopez GE, Banegas BJ, Rodriguez AF. Work-related physical activity is not associated with body mass index and obesity. Obes Res. 2002;10:270-276.

11. Berlin JA, Colditz GA. A meta-analysis of physical activity $n$ the prevention of coronary heart disease. Am J Epidemiol. 1990;132:612-628.

12. Crespo CJ, Keteyian SJ, Heath GW. et al. Leisure-time physical activity among US adults. Results from the Third National Health and Nutrition Examination Survey. Arch Intern Med. 1996;156(1):93-98.

13. Crespo CJ, Smit E, Carter-Pokras O, Andersen R. Acculteration and leisure-time inactivity in Mexican-American adults: Results from the NHANES III, 1988-1994. Am J Public Health. 2001;91(8):1254-1257.

14. Bolen JC, Rhodes L, Powell-Griner EE, Bland SD, Holtzman D. Statespecific prevalence of selected health behaviors, by race and ethnicityBehavioral Risk Factor Surveillance System, 1997. MMWR CDC Surveill Summ. 2000;49(2): 1-60.

15. Bazzano LA, He J, Ogden LG, et al. Fruit and vegetable intake and risk of cardiovascular disease in US adults: the first National Health and Nutrition Examination Survey Epidemiologic Follow-up Study. Am J Clin Nutr. 2002;76(1):93-99.

16. Eyre H, Kahn R, Robertson RM. Preventing cancer, cardiovascular disease, and diabetes: a common agenda for the American Cancer Society, the American Diabetes Association, and the American Heart Association. Diab Care. 2004;27(7):1812-1824.

17. National Research Council. Critical perspectives on racial and ethnic differences in health in late life. Washington, D.C.: The National Academies Press; 2004.

18. Dubowitz T, Heron M, Bird CE, et al. Neighborhood socioeconomic status and fruit and vegetable intake among whites, blacks, and Mexican Americans in the United States. Am J Clin Nutr. 2008;87(6):1883-1891.

19. Jasso G, Massey DS, Rosenzweig MR, Smith JP. The New Immigrant Survey Pilot (NIS-P): Overview and new findings about U.S. legal immigrants at admission. Demography. 2000;37:127-138.

20. Espino DV, Burge SK, Moreno CA. The prevalence of selected chronic diseases among Mexican-American elderly: Data from 1982-1984 Hispanic Health and Nutrition Examination Survey. J Am Board Fam Pract. 1991;4:217-222.

21. Duffey KJ, Gordon-Larsen P, Ayala GX, Popkin BM. Birthplace Is associated with more adverse dietary profiles for US-born than for foreign-born Latino adults. J Nutr. 2008;138:2428-2435.

22. Neuhouser ML, Thompson B, Coronado GD, Solomon CC. Higher fat intake and lower fruit and vegetables intakes are associated with greater acculturation among Mexicans living in Washington State. J Am Diet Assoc. 2004; 104(1):51-57.

23. August KJ, Sorkin DH. Racial and ethnic disparities in indicators of physical health status: Do they exist throughout late life? JAGS. In press.

24. Idler EL. Age differences in self-assessments of health: age changes, cohort differences, or survivorship? J Gerontol. 1993;48(6):S289-S300.

25. California Health Interview Survey. CHIS Survey Methology and Sample Design. 2006; http://www.chis.ucla.edu/methods_main.html. Accessed September 4, 2010.

26. Centers for Disease Control and Prevention. Nutrition for everyone: Fruits and vegetables. http://www.cdc.gov/nutrition/everyone/fruitsve getables/index.html. Accessed January 28, 2010.

27. Bowman SA. Socioeconomic characteristics, dietary and lifestyle patterns, and health and weight status of older adults in NHANES, 19992002: a comparison of Caucasians and African Americans. J Nutr Elder. 2009;28(1):30-46.

28. Sundquist J, Winkleby MA, Pudaric S. Cardiovascular disease risk factors among older black, Mexican American, and white women and men: An analysis of NHANES III, 1988-1994. J Am Geriatr Soc. 2001;49:109-116.

29. Kruger J, Ham SA, Sanker S. Physical inactivity during leisure time among older adults-Behavioral Risk Factor Surveillance System, 2005. J Aging Phys Act. 2008;16(3):280-291.

30. Kandula NR, Lauderdale DS. Leisure time, non-leisure time, and occupational physical activity in Asian Americans. Ann Epidemiol. 2005; 15(4):257-265. 
31. Caperchione CM, Kolt GS, Mummery WK. Physical activity in culturally and linguistically diverse migrant groups to Western society: a review of barriers, enablers and experiences. Sports Med. 2009;39(3):167-177.

32. Crespo CJ, Smit E, Andersen RE, Carter-Pokras O, Ainsworth BE. Race/ethnicity, social class and their relation to physical inactivity during leisure time: results from the Third National Health and Nutrition Examination Survey, 1988-1994. Am J Public Health. 2000; 18(1):46-53.

33. Marshall SJ, Jones DA, Ainsworth BE, Reis JP, Levy SS, Macera CA. Race/ethnicity, social class, and leisure-time physical inactivity. Med Sci Sports Exerc. 2006;39:44-51.

34. Corral I, Landrine H. Acculturation and ethnic-minority health behavior: a test of the operant model. Health Psychol. 2008;27(6):737-745.

35. Belza B, Walwick J, Shiu-Thornton S, Schwartz S, Taylor M, LoGerfo J. Older adult perspectives on physical activity and exercise: voices from multiple cultures. Prev Chronic Dis. 2004;1(4):A09.

36. Mathews AE, Laditka SB, Laditka JN, et al. Older adults' perceived physical activity enablers and barriers: a multicultural perspective. J Aging Phys Act. 2010;18(2):119-140.

37. Plonczynski DJ. Physical activity determinants of older women: what influences activity. Medsurg Nurs. 2003;12(4):213-221. 259; quiz 222.

38. Lee RE, Cubbin C, Winkleby M. Contribution of neighbourhood socioeconomic status and physical activity resources to physical activity among women. J Epidemiol Community Health. 2007;61 (10):882-890.

39. Abraido-Lanza AF, Chao MT, Florez KR. Do healthy behaviors decline with greater acculturation? Implications for the Latino mortality paradox. Soc Sci Med. 2005;61(6): 1243-1255.
40. Drewnowski A, Darmon N, Briend A. Replacing fats and sweets with vegetables and fruits-a question of cost. Am J Public Health. 2004;94 (9): 1555-1559.

41. Mensah GA, Mokdad AH, Ford ES, Greenlund KJ, Croft JB. State of disparities in cardiovascular health in the United States. Circulation. 2005;111(10):1233-1241.

42. Patterson RE, Kristal AR, White E. Do beliefs, knowledge, and perceived norms about diet and cancer predict dietary change? Am J Public Health. 1996;86:1394-1400.

43. Savoca MR, Arcury TA, Leng $\mathbf{X}$, et al. The diet quality of rural older adults in the South as measured by healthy eating index-2005 varies by ethnicity. J Am Diet Assoc. 2009;109(12):2063-2067.

44. Marquez DX, Neighbors CJ, Bustamante EE. Leisure time and occupational physical activity among racial/ethnic minorities. Med Sci Sports Exerc. 2010; 42(6):1086-1093.

45. Carcaise-Edinboro P, McClish D, Kracen AC, Bowen D, Fries E. Fruit and vegetable dietary behavior in response to a low-intensity dietary intervention: the rural physician cancer prevention project. J Rural Health. 2008;24(3):299-305.

46. Bopp M, Lattimore $\mathbf{D}$, Wilcox $\mathbf{S}$, et al. Understanding physical activity participation in members of an African American church: a qualitative study. Health Educ Res. 2007;22(6):815-826.

47. Wellman NS, Kamp B, Kirk-Sanchez NJ, Johnson PM. Eat better \& move more: a community-based program designed to improve diets and increase physical activity among older Americans. Am J Public Health. 2007;97(4):710-717.

48. Frank L, Kerr J, Rosenberg D, King A. Healthy aging and where you live: community design relationships with physical activity and body weight in older Americans. J Phys Act Health. 2010;7(Suppl 1):S82-S90. 